\title{
QUALIDADE FÍSICA DE OVOS ARMAZENADOS EM DIFERENTES CONDIÇÕES DE EMBALAGENS SOB TEMPERATURA AMBIENTE
}

\author{
PHYSICAL QUALITATIVE OF STORED EGGS IN DIFFERENT PACKING CONDITION ON \\ ROOMTEMPERATURE
}

\author{
Scatolini-Silva, A.M. ${ }^{1 *}$; Borba, H. ${ }^{1 \mathrm{~A}}$; Giampietro-Ganeco, A. ${ }^{1 \mathrm{~B}}$; Souza, P.A. ${ }^{1 \mathrm{C}}$; Boiago, M.M. ${ }^{2}$; \\ Mello, J.L.M. ${ }^{1 \mathrm{D}}$ e Vaz, A.B.S. ${ }^{1 \mathrm{E}}$
}

\begin{abstract}
'Departamento de Tecnologia. FCAV/UNESP. Jaboticabal-SP. Brasil. *alinescatolini@yahoo.com.br;

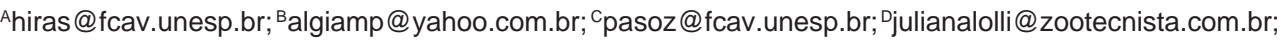
Ealinebuda@zootecnista.com.br

²Departamento de Zootecnia.CEO/UDESC.Chapecó-SC.Brasil.mmboiago@gmail.com
\end{abstract}

\section{Palavras chave adicionais}

Qualidade interna. Vácuo.

\section{RESUMO}

Avaliou-se a qualidade interna de ovos de casca branca, higienizados ou não, armazenados em diferentes condições de embalagens, sob temperatura ambiente. Trezentos ovos foram distribuídos em um DIC em esquema fatorial $3 \times 2 \times 4+1$ (3 embalagens: filme PVC, vácuo parcial e vácuo parcial com sequestrantes de gás oxigênio; 4 períodos de armazenamento: 7, 14, 21 e 28 dias; higienizados ou não; e testemunha, ovos frescos, com 4 repetições). As análises foram realizadas ao final de cada período. O vácuo parcial manteve a unidade Haugh dos ovos, e proporcionou os melhores resultados para índice gema. A manutenção de peso dos ovos foi melhor quando embalados em condição de vácuo, com ou sem sachês sequestrantes de $\mathrm{O}_{2}$. Menores valores de atividade de água foram obtidos nos ovos embalados em filme de PVC, e quando realizada a higienização. Conclui-se que a qualidade interna dos ovos decresceu com o tempo de estocagem de forma mais acentuada nos ovos embalados em filme plástico, já que a condição de vácuo preservou algumas características. Com a higienização, as condições de armazenamento dos ovos em filme de PVC devem ser melhoradas, pois a qualidade interna destes foi a mais reduzida.

\section{SUMMARY}

The objective was to evaluate the internal

\author{
Additional KEYWORDS \\ Internal quality. Vacuum.
}

quality of white-shelled consume eggs, sanitized or not, stored under different packaging conditions at room temperature. It was used 300 eggs, distributed in a completely randomized experimental design in a $3 \times 2 \times 4+1$ factorial arrangement, three packaging conditions (PVC film, partial vacuum, partial vacuum with oxygen gas absorber), storage period (7, 14, 21 and 28 days), sanitized or not, and control (fresh eggs), with four repetitions. At the end of each period the analysis were performed. Partial vacuum condition was able to maintained Haugh unit, and promoted the best results for yolk index. The weight maintenance was better when packaged under vacuum, with or without $\mathrm{O}_{2}$ sachets absorbers. Lower values of water activity were obtained in eggs packed in PVC film, and when the sanitation was performed. It can be concluded that the internal egg quality decreases with storage time sharper in the eggs packed in PVC film, because vacuum has preserved some features of them. With sanitation, the storage conditions of eggs in PVC film should be improved because its internal quality decrease was greatest.

\section{INTRODUÇÃO}

A transformação depende de fatores biológicos relacionados à fisiologia da ave e é influenciada pelo aporte nutricional e 
práticas de manejo e ambiente adequado para a sua criação (Bertechini, 2004).

O objetivo principal em produzir ovos para consumo humano é proporcionar ao consumidor a qualidade original desse produto. O principal problema relacionado com a qualidade do ovo é a sua manutenção nos canais de comercialização. Portanto, o conhecimento do processamento da produção, da comercialização e dos métodos de mensuração da qualidade do ovo são muito importantes para o consumidor (Moreng e Avens, 1990).

Inúmeros fatores internos determinam a qualidade do ovo: valor nutricional, sabor, odor, cor da gema, palatabilidade e aparência são fatores de qualidade que não são facilmente determinados na aquisição do produto. Apesar de haver uma diferença na aparência entre ovo fresco e ovo velho, não foi demonstrada diferença nutricional entre os dois (Englert, 1998).

Contudo, ovos são perecíveis e perderão a qualidade se não forem adequadamente manipulados. Do momento da postura até o processamento e comercialização do ovo, o principal objetivo é preservar ao máximo sua qualidade original até que ele chegue ao consumidor. $\mathrm{O}$ armazenamento doméstico adequado feito pelo consumidor após o ovo deixar o mercado também é muito importante. A principal alteração da qualidade é conseqüência à perda de água através dos poros da casca pela evaporação, que diretamente influencia o tamanho da câmara de ar. A evaporação da água depende do ambiente em que o ovo é estocado, da temperatura, da umidade relativa e da ventilação (Moreng e Avens, 1990).

Algumas estratégias devem ser aplicadas pelo setor de postura devido à ausência da refrigeração dos ovos nos pontos comerciais. Dentre elas as embalagens assumem grande importância quando levados em consideração os critérios utilizados pelos consumidores no momento da escolha do produto nas gôndolas dos supermercados, bem como na manutenção da qualidade dos ovos. Considerando que o ovo é um produto natural, não se distinguindo entre as diferentes granjas produtoras, a embalagem passa a ter o importante papel de diferenciação, condicionando o consumidor a determinadas marcas. Várias empresas têm investido na modernização de suas embalagens, tornando-as mais atraentes, práticas, e com papel fundamental de acondicionamento e proteção da qualidade dos ovos de consumo como forma de despertar o interesse dos consumidores (Antunes, 2001).

Mediante o exposto, o presente estudo teve a proposta de avaliar as características físicas de ovos de casca branca, armazenados em diferentes embalagens sob condições de ambiente, higienizados ou não.

\section{MATERIALE MÉTODOS}

O experimento foi conduzido no Laboratório de Tecnologia dos Produtos de Origem Animal do Departamento de Tecnologia da Faculdade de Ciências Agrárias e Veterinárias da Unesp, Câmpus de Jaboticabal, SP. As análises foram realizadas de janeiro a fevereiro de 2010.

Foram utilizados para a determinação das características físicas 300 ovos de casca branca, todos sem trincas e classificados como grandes, provenientes de poedeiras leves (Hy Line W-36), com 56 semanas de idade, e mesmo sistema de criação.

Metade destes ovos foi coletada antes da higienização realizada nas granjas, e a outra metade após. Os ovos foram lavados mecanicamente em água clorada (50 ppm) a $35-40{ }^{\circ} \mathrm{C}$ (Brasil, 1990).

Após os procedimentos, realizados na Cooperativa Agrícola da cidade de Guatapará - SP, os ovos foram transportados para o Laboratório da FCAV (Jaboticabal) em aproximadamente uma hora, sob condições de temperatura ambiente. Em seguida, realizou-se a distribuição em 24 tratamentos, ou seja, foram divididos em dois grupos (higienizados e não higienizados), distri- 
buídos em bandejas de PET (politereftalato de etileno) para uma dúzia de ovos e submetidos a três condições de embalagens utilizadas: filme PVC (filme plástico de poli cloreto de vinila), vácuo parcial e vácuo parcial com sachês sequestrantes de gás oxigênio.

Dessa forma, um terço das bandejas com uma dúzia de ovos foi embalada em filme de PVC, e os outros dois terços foram recobertas por sacolas plásticas Protervac $\AA$ $\left(0,1 \mathrm{~mm},<85 \mathrm{O}_{2} \mathrm{cc} / \mathrm{m}^{2} / 24 \mathrm{~h}\right.$ a $\left.23^{\circ} \mathrm{C}\right) \mathrm{com}$ as seguintes dimensões: $20 \mathrm{~cm}$ (largura) x 51 $\mathrm{cm}$ (comprimento) x $180 \mu$ (espessura). Nestas últimas, foi realizado o vácuo parcial em embaladora a vácuo Selovac® 200 B.

Os sachês sequestrantes de $\mathrm{O}_{2}$ tinham capacidade de absorver 50 cc de gás oxigênio, sendo elaborado por um composto químico em pó, a base de óxido de ferro e zeolite. Assim, a quantidade de sachês sequestrantes de $\mathrm{O}_{2}$ no interior das embalagens foi estipulada de acordo com a perda de peso dos ovos (Scatolini-Silva et al., 2010), as dimensões da embalagem e a capacidade de absorção dos mesmos (conforme especificações do fabricante).

Os ovos foram armazenados durante quatro períodos $(7,14,21$ e 28 dias), sob temperatura ambiente, e as análises iniciais dos ovos frescos higienizados (testemunha) se procederam imediatamente após o embalamento (dia 0$)$.

As médias, mínimas e máximas, das temperaturas foram de 21,2 e $33^{\circ} \mathrm{C}$, respectivamente, com média de umidade relativa de $57 \%$ durante o período de estudo.

Foi utilizado o delineamento inteiramente casualizado em esquema fatorial $3 \times 2 \times 4+1$ (condições de embalagem, higienização ou não, e períodos de armazenamento + testemunha-ovos frescos), com 4 repetições de 3 ovos cada. Foi verificada a homogeneidade da variância (através do teste de Bartlett), utilizando o GLM Procedure do sistema operacional SAS $®$ (1999). E em seguida as médias dos resultados obtidos foram comparadas pelo teste de Tukey a $5 \%$ de significância.
A cada sete dias, a partir do tempo zero, quatro bandejas de cada tratamento foram desembaladas. As análises foram realizadas em triplicata, e os ovos foram submetidos às seguintes análises de qualidade das características físicas:

- Manutenção de peso durante armazenamento: no início do experimento, os ovos foram individualmente pesados utilizando-se balança com precisão de $0,001 \mathrm{~g}$ e armazenados de acordo com cada tratamento especificado sob temperatura ambiente. No final de cada período foram pesados novamente, e pela diferença do peso inicial e final foi obtida a percentagem da manutenção de peso.

- Qualidade do albúmen: foi avaliada utilizando a unidade Haugh, conforme descrito em Card e Nesheim (1978), ou seja, depois de individualmente pesados em balança de precisão, os ovos foram quebrados sobre mesa especial de vidro, onde foi medida a altura do albúmen com auxílio de altímetro especial (Egg Quality Micrometer). De posse dos dados de peso (g) e altura (mm), foi calculada a unidade Haugh mediante a seguinte equação:

$$
\mathrm{UH}=100 \log (\mathrm{H}+7,57-1,7 \mathrm{~W} 0,37)
$$

onde:

$\mathrm{UH}=$ unidade Haugh;

$\mathrm{H}=$ altura do albúmen (em milímetros);

$\mathrm{W}=$ peso do ovo (em gramas).

- Qualidade da gema: foi avaliada pela obtenção do índice gema, ou seja, medindose a altura da gema através de altímetro especial (Egg Quality Micrometer) e o diâmetro da gema com paquímetro. A relação entre estes dois parâmetros forneceu o índice gema:

$$
I G=A G / D G
$$

onde:

$\mathrm{IG}$ = índice gema;

$A G=$ altura da gema (em milímetros);

$\mathrm{DG}=$ diâmetro da gema (em milímetros). 
- Atividade de água (Aw): gema e albúmen foram misturados e uma parte da amostra foi colocada no compartimento do analisador de atividade de água Aqualab (Decagon Devices Inc.), que utiliza o princípio do ponto de orvalho, metodologia aprovada pela AOAC (1984).

\section{RESULTADOSEDISCUSSÃO}

As médias obtidas para a qualidade física dos ovos de casca branca, tais como: unidade Haugh (UH), índice gema (IG), manutenção de peso dos ovos em porcentagem (\% MPO) e atividade de água (Aw) estão apresentadas na tabela I. Houve interação entre os fatores período de armazenamento $\mathrm{x}$ embalagem para as características de UH, IG, \% MPO e Aw; entre os fatores período de armazenamento $\mathrm{x}$ higienização para as características \% MPO e Aw; e entre embalagens x higienização para IG e \% MPO. Exceto para a característica UH, os três fatores estudados (período $\mathrm{x}$ embalagem x higienização) interagiram entre si para as demais características.

Pode-se observar na tabela I que para todas as características estudadas houveram diferenças estatísticas $(\mathrm{p}<0,05)$ entre o tratamento testemunha e o grupo fatorial. Os ovos frescos (testemunha), apresentaram valores superiores quando comparados aos armazenados, embalados e não higienizados. A higienização dos ovos não alterou o valor da UH. O desdobramento da interação entre o período de armazenamento e embalagens para a característica unidade Haugh dos ovos estão na tabela II.

Observou-se aqui no estudo que a qualidade interna dos ovos decresce com armazenamento de 28 dias (tabela II), conforme encontrado na literatura (Haugh 1937; Alleoni e Antunes, 2001). Porém, os ovos embalados em condição de vácuo parcial apresentaram melhores valores de UH quando comparados às demais condições $(\mathrm{p}<0,01)$, o que mostra boa qualidade interna desses ovos já que um valor de UH acima
Tabela I. Médias obtidas para unidade Haugh (UH), índice gema (IG), manutenção de peso (\% MPO) e atividade de água $(A w)$ dos ovos armazenados em diferentes embalagens. (Averages obtained for Haugh unit (UH), yolk index (IG), weight maintenance and water activity of eggs stored in different packaging).

\begin{tabular}{|c|c|c|c|c|}
\hline & $\mathrm{UH}$ & IG & $\%$ MPO & $A w$ \\
\hline \multicolumn{5}{|c|}{ Testemunha vs. fatorial } \\
\hline Testemunha & $87,56^{A}$ & $0,43^{\mathrm{A}}$ & $100,00^{A}$ & $0,950^{\mathrm{B}}$ \\
\hline Fatorial & $64,55^{\mathrm{B}}$ & $0,31^{\mathrm{B}}$ & $98,63^{\mathrm{B}}$ & $0,965^{A}$ \\
\hline Teste F & $89,46^{* *}$ & $185,12^{* *}$ & * $323,59^{* *}$ & $82,48^{* *}$ \\
\hline \multicolumn{5}{|l|}{ Higienização } \\
\hline Sim & 64,27 & - & - & - \\
\hline Não & 64,82 & - & - & - \\
\hline Teste F & $0,32^{\mathrm{NS}}$ & - & - & - \\
\hline F Int. PxE & $7,11^{* *}$ & $15,94^{* *}$ & $307,59^{* *}$ & $3,71^{* *}$ \\
\hline F Int. PxH & $0,12^{\mathrm{NS}}$ & $1,84 \mathrm{NS}$ & $3,15^{\star}$ & $13,10^{\text {** }}$ \\
\hline F Int. ExH & $0,73^{\mathrm{NS}}$ & $21,83^{* *}$ & $4,45^{*}$ & $0,20^{\mathrm{NS}}$ \\
\hline FInt. PxExH & $1,13^{\mathrm{NS}}$ & $2,41^{*}$ & $3,56^{* *}$ & $10,54^{* *}$ \\
\hline CV (\%) & 7,28 & 5,46 & 0,15 & 0,33 \\
\hline
\end{tabular}

$\mathrm{P}=$ período de armazenamento; $\mathrm{E}=$ tipos de embalagem; $\mathrm{H}=$ higienização.

ABNa mesma coluna, médias seguidas de letras iguais não diferem entre si pelo teste de Tukey $\left.(5 \%) .{ }^{*} p<0,05\right) ;{ }^{* *} p<0,01 . \quad C V=$ coeficiente de variação. NS= não significativo.

de 60 é considerado de qualidade. O Programa de Controle da Qualidade preconizado pelo United States Department of Agriculture (USDA) define as condições que devem ser encontradas desde quando o ovo é produzido até o seu consumo pela população. Para tal, ovos considerados de qualidade excelente (AA) devem apresentar valores de UH superiores a 72; ovos de qualidade alta (A), entre 60 e $72 \mathrm{UH}$, e ovos de qualidade inferior (B), com valores de UH inferiores a 60 (USDA, 2000). Leonel et al. (2007) também encontraram superioridade da condição de vácuo no armazenamento de ovos para esta característica quando ovos em condição de vácuo e filme de PVC foram 


\section{QUALIDADE FÍSICA DE OVOS ARMAZENADOS EM DIFERENTES EMBALAGENS}

armazenados em temperatura ambiente.

Os desdobramentos das interações entre período de armazenamento e embalagens, e entre embalagens e higienização para a característica índice gema dos ovos encontram-se na tabela III.

Na tabela III notou-se mais uma vez a eficácia da condição de vácuo parcial na preservação da qualidade interna dos ovos, pois em todos os períodos de armazenamento e sendo higienizados ou não, proporcionou melhores resultados para o índice gema. Na embalagem em condição de vácuo com sequestrante de $\mathrm{O}_{2}$, os ovos não higienizados mostraram valores de índice gema superiores aos que foram higienizados. Fato que pode ser decorrente da retirada da película de proteção natural da casca do ovo (poros parcialmente selados por proteína) com a higienização, e esta favorecer maiores trocas gasosas entre ovo $\mathrm{x}$ ambiente interno da embalagem. Pois segundo Pombo (2003), ao estudar o efeito do tratamento térmico de ovos inteiros na perda de peso e características de qualidade interna, verificou que as trocas gasosas são responsáveis pela liquefação do albúmen e, consequentemente, em um ovo estocado, a

Tabela II. Desdobramento da interação entre período de armazenamento e embalagens para a unidade Haugh dos ovos. (Interaction sliced of storage period and packaging for the egg Haugh unit).

\begin{tabular}{|c|c|c|c|}
\hline \multicolumn{4}{|c|}{ Armazenamento em dias } \\
\hline & 14 & 21 & 28 \\
\hline \multicolumn{4}{|l|}{ Embalagem } \\
\hline Filme & $71,58^{\mathrm{Ba}} 55,84^{\mathrm{Bb}}$ & $42,41^{\mathrm{cc}} 5$ & $50,42^{\mathrm{Bbc}}$ \\
\hline Vácuo parcial & $83,83^{\mathrm{Aa}} 76,71^{\mathrm{Aab}}$ & $72,65^{\mathrm{Ab}}$ & $70,60^{A b}$ \\
\hline Vácuo+Seq. $\mathrm{O}_{2}$ & $278,27^{\mathrm{ABa}} 63,58^{\mathrm{Bb}}$ & $57,41^{\mathrm{Bb}}$ & $51,27^{\mathrm{Bb}}$ \\
\hline \multicolumn{4}{|c|}{$\begin{array}{l}\text { ABCNa mesma coluna, médias seguidas de letras } \\
\text { maiúsculas iguais não diferem entre si pelo teste } \\
\text { de Tukey (5\%); abcna mesma linha, médias segui- } \\
\text { das de letras minúsculas iguais não diferem entre } \\
\text { si pelo teste de Tukey (5\%). }\end{array}$} \\
\hline
\end{tabular}

Tabela III. Desdobramentos das interações entre periodo de armazenamento (dias) e embalagem e entre embalagem $x$ higienização para o índice gemadosovos. (Interactions sliced of storage (days) period $x$ packaging, and packaging $x$ sanitation for the egg yolk index).

\begin{tabular}{|c|c|c|c|c|c|}
\hline & \multicolumn{4}{|c|}{ Embalagem $\mathrm{x}$ armazenamento } \\
\hline & & $7 d$ & $14 \mathrm{~d}$ & $21 d$ & $28 d$ \\
\hline \multicolumn{2}{|c|}{ Filme } & $0,36^{\mathrm{Ba}}$ & $0,27^{\mathrm{Bb}}$ & $0,22^{\mathrm{cc}}$ & $0,20^{\mathrm{cc}}$ \\
\hline \multicolumn{2}{|c|}{ Vácuo parcial } & $0,41^{\mathrm{Aa}}$ & $0,37^{\mathrm{Ab}}$ & $0,35^{\mathrm{Abc}}$ & $0,33^{\mathrm{Ac}}$ \\
\hline \multicolumn{2}{|c|}{ Vácuo+Seq. $\mathrm{O}_{2}$} & $0,39^{A b a}$ & $0,26^{\mathrm{Bb}}$ & $0,27^{\mathrm{Bb}}$ & $0,24^{\mathrm{Bb}}$ \\
\hline & \multicolumn{5}{|c|}{ Higienização x embalagem } \\
\hline & Filme & \multicolumn{2}{|c|}{ Vácuo parcial } & \multicolumn{2}{|c|}{ Vácuo+Seq. $\mathrm{O}_{2}$} \\
\hline Sim & $0,27^{A b}$ & \multicolumn{2}{|c|}{$0,36^{\mathrm{Aa}}$} & \multicolumn{2}{|c|}{$0,26^{\mathrm{Bb}}$} \\
\hline Não & $0,26^{A C}$ & \multicolumn{2}{|c|}{$0,37^{\mathrm{Aa}}$} & \multicolumn{2}{|c|}{$0,31^{A b}$} \\
\hline
\end{tabular}

${ }^{A B C} \mathrm{Na}$ mesma coluna, médias seguidas de letras maiúsculas iguais não diferem entre si pelo teste de Tukey (5\%); ${ }^{\text {bc }}$ na mesma linha, médias seguidas de letras minúsculas iguais não diferem entre si pelo teste de Tukey (5\%).

gema absorve água deste albúmen liquefeito.

Os valores médios de índice gema para ovos frescos situam-se entre 0,42 e 0,40 (Souza, 1997), o que condiz com os valores obtidos para ovos frescos aqui no estudo. Porém, quando o valor de índice gema for inferior a 0,25 , a gema é muito frágil e tornase muito difícil a realização de medições sem que se rompa (Card e Nesheim, 1978), assim como observado nos ovos embalados em filme plástico à partir dos 21 dias de armazenamento.

Dados semelhantes aos obtidos neste estudo, para o índice gema, foram também observados por Leonel et al. (2007), que ao estudarem ovos armazenados em filme de PVC e vácuo obtiveram valores em torno de 0,35 para índice gema de ovos armazenados durante 28 dias em condição de vácuo. Além de observarem também superioridade do vácuo em relação ao filme de PVC para a manutenção desta característica.

Essas observações, novamente demons- 
tram que a perda de $\mathrm{CO}_{2}$ através da casca do ovo é uma das principais causas da deterioração do albúmen, pois provocam a degradação das proteínas no albúmen espesso. Souza (1997) descreveu que tal processo ocorre porque as enzimas que atuam sobre essas proteínas, hidrolisam as cadeias de aminoácidos e liberam a água que se encontra ligada às moléculas das proteínas. Por osmose, esta água liberada no albúmen, atravessa a membrana vitelina e é retida pela gema, que é mais concentrada. $\mathrm{O}$ acúmulo de água na gema provoca o enfraquecimento da membrana vitelina e esta se rompe liquefazendo também a gema colaborando para a diminuição do índice gema dentre outros fatores de qualidade.

Na tabela IV são mostrados os desdobramentos dos três fatores estudados (período de armazenamento, embalagem e higienização) para a característica de manutenção de peso dos ovos. Nota-se a pouca eficiência do filme plástico como barreira para impedir a perda de peso dos ovos armazenados em todos os períodos, pois esses apresentaram menores \% MPO quando comparados aos ovos das demais embalagens $(\mathrm{p}<0,05)$. Segundo a literatura, a redução de peso dos ovos pode também ser determinada pela provável perda de amônia, nitrogênio e sulfeto de hidrogênio, que são produtos da degradação química de seus constituintes orgânicos (Solomon, 1991; Silversides e Budgell, 2004) e liberação de dióxido de carbono e umidade (Stadelman \& Cotterill, 1977). Assim, este estudo mostra a capacidade do vácuo em minimizar as reações químicas entre ovo e ambiente, minimizando também as perdas de gases e água.

Pode-se observar que ao longo da estocagem a perda de peso dos ovos foi crescente, pois segundo Stadelman e Cotterill (1977), a evaporação da água do ovo é um processo contínuo, tendo início no momento da postura, não cessando até que esteja completamente desidratado.

Com relação à higienização, os ovos armazenados por 28 dias e os que foram embalados em filme plástico mostraram-se piores em manter o peso quando higienizados. O que mais uma vez mostra o rompimento da barreira existente nos poros da casca dos ovos (cutícula protetora) com a higienização, que favorece maiores liberações de água e gases. Stringhini et al. (2009) citaram ainda que a desvantagem da lavagem dos ovos é a remoção da cutícula protetora dos poros da casca, facilitando a entrada de microrganismos e resultando na deterioração e diminuição do período de estocagem.

Boiago et al. (2006), ao avaliarem a

Tabela IV. Desdobramento das interações entre período de armazenamento (dias) e embalagens, período de armazenamento e higienização, e entre embalagem e higienização para porcentagem de manutenção de peso (\% MPO) dos ovos. (Interactions sliced of storage (days) period $x$ packaging, and packaging $x$ sanitation, and storage period $x$ sanitation for the eggs weight maintenance).

\begin{tabular}{|c|c|c|c|c|c|}
\hline & & \multicolumn{4}{|c|}{ Embalagem $x$ armazenamento } \\
\hline & & $7 d$ & $14 d$ & $21 d$ & $28 d$ \\
\hline \multicolumn{2}{|l|}{ Filme } & $98,64^{\mathrm{Ba}}$ & $97,52^{\mathrm{Bb}}$ & $95,86^{\mathrm{BC}}$ & $94,68^{B d}$ \\
\hline \multicolumn{2}{|c|}{ Vácuo parcial } & $99,82^{\mathrm{Aa}}$ & $99,77^{\text {Aab }}$ & $99,49^{\mathrm{Ab}}$ & $99,51^{\mathrm{Ab}}$ \\
\hline \multirow{3}{*}{\multicolumn{2}{|c|}{ Vácuo+Seq. $O_{2}$}} & $99,74^{\mathrm{Aa}}$ & $99,66^{\text {Aa }}$ & $99,50^{\mathrm{Aab}}$ & $99,40^{A b}$ \\
\hline & & \multicolumn{4}{|c|}{ Higienização x armazenamento } \\
\hline & & $7 \mathrm{~d}$ & $14 \mathrm{~d}$ & $21 d$ & $28 \mathrm{~d}$ \\
\hline \multicolumn{2}{|l|}{$\operatorname{Sim}$} & $99,37^{\mathrm{Aa}}$ & $98,95^{\mathrm{Ab}}$ & $98,27^{\mathrm{AC}}$ & $97,74^{\mathrm{Bd}}$ \\
\hline \multirow[t]{3}{*}{ Não } & & $99,42^{\mathrm{Aa}}$ & $99,00^{A b}$ & $98,30^{A C}$ & $97,99^{\mathrm{Ad}}$ \\
\hline & & \multicolumn{4}{|c|}{ Higienização x embalagem } \\
\hline & Filme & \multicolumn{2}{|c|}{ Vácuo parcial } & \multicolumn{2}{|c|}{ Vácuo+Seq. $\mathrm{O}_{2}$} \\
\hline Sim & $96,56^{\mathrm{Bb}}$ & \multicolumn{2}{|c|}{$99,62^{\mathrm{Aa}}$} & \multicolumn{2}{|c|}{$99,57^{\text {Aa }}$} \\
\hline Não & $96,79^{A b}$ & \multicolumn{2}{|c|}{$99,67^{\text {Aa }}$} & \multicolumn{2}{|c|}{$99,58^{\mathrm{Aa}}$} \\
\hline
\end{tabular}

ABNa mesma coluna, médias seguidas de letras maiúsculas iguais não diferem entre si pelo teste de Tukey (5\%); abcdna mesma linha, médias seguidas de letras minúsculas iguais não diferem entre si pelo teste de Tukey (5\%). 
utilização de filme de PVC no armazenamento de ovos de duas diferentes linhagens de poedeiras, sob condição de temperatura ambiente, notaram que essa barreira mostrou eficiência em retardar a velocidade de deterioração. No presente estudo, as reações químicas para perda de peso dos ovos foram minimizadas em condição de vácuo parcial, com ou sem saches sequestrantes de gás $\mathrm{O}_{2}$. Isto é, ovos embalados em condição de vácuo e com sachês que sequestram o $\mathrm{O}_{2}$ residual em seu interior, consequentemente tiveram impedida a perda de $\mathrm{CO}_{2}$, através da casca. E assim, todas as reações químicas de perda de gases e umidade foram menores, minimizando a perda de peso dos mesmos.

Os desdobramentos para as interações entre períodos de armazenamento e embalagens e entre períodos de armazenamento e higienização referentes à característica de Aw dos ovos são mostrados na tabela $\mathbf{V}$. Com o armazenamento, a Aw dos ovos aumenta (tabela V), e isso mostra que o envelhecimento do ovo o torna mais susceptível à deterioração. Pois a Aw de água é uma medida que está ligada à umidade do alimento variando de 0 a 1 , e que permite determinar sua capacidade de conservação, de propagação microbiana etc. Trata-se de um dos fatores que mais influenciam na estabilidade dos produtos alimentícios. E no presente estudo a Aw dos ovos embalados em filme de PVC foram menores $(\mathrm{p}<0,01)$ quando comparadas aos ovos embalados em condição de vácuo com sequestrante de $\mathrm{O}_{2}$ em todos os períodos analisados. Talvez essa menor Aw nos ovos em filme de PVC esteja relacionada com sua menor \% MPO, já que parte da água é perdida nas trocas evaporativas entre ovo e ambiente. Ovos não higienizados mostraram maior $\mathrm{Aw}$ ao final do armazenamento, o que mostra que a falta de higienização poder comprometer ovos principalmente por maiores períodos de estocagem.

Baseando-se na Aw como indicativo de
Tabela $\boldsymbol{V}$. Desdobramentos das interações entre período (dias) de armazenamento e embalagens, e entre período de armazenamento e higienização para Aw dos ovos de casca branca. (Interactions sliced of storage (days) period $x$ packaging, and storage period $x$ sanitation for the eggs water activity).

\begin{tabular}{|c|c|c|c|c|}
\hline & Emba & alagem $x a$ & armazen & amento \\
\hline & $7 d$ & $14 \mathrm{~d}$ & $21 d$ & $28 d$ \\
\hline Filme & $0,954^{\mathrm{Bc}}$ & $0,962^{\mathrm{Bab}}$ & $0,960^{\mathrm{Bb}}$ & $0,967^{\mathrm{Ba}}$ \\
\hline Vácuo parcial & $0,957^{\mathrm{AbC}}$ & $0,967^{\mathrm{Ab}}$ & $0,964^{\mathrm{ABB}}$ & $0,977^{\mathrm{Aa}}$ \\
\hline Vácuo+Seq.O & ${ }_{2} 0,962^{\mathrm{Ab}}$ & $0,966^{\mathrm{Ab}}$ & $0,965^{\mathrm{Ab}}$ & $0,974^{\mathrm{Aa}}$ \\
\hline & Higieni & zação x a & armazen & amento \\
\hline & $7 d$ & $14 \mathrm{~d}$ & $21 d$ & $28 d$ \\
\hline Sim & $0,956^{\mathrm{Ac}}$ & $0,967^{\mathrm{Aa}}$ & $0,960^{\mathrm{Bb}}$ & $0,970^{\mathrm{Ba}}$ \\
\hline Não & $0,959^{A C}$ & $0,963^{\mathrm{Bbc}}$ & $0,965^{\mathrm{Ab}}$ & $0,976^{\mathrm{Aa}}$ \\
\hline
\end{tabular}

${ }^{\mathrm{AB}} \mathrm{Na}$ mesma coluna, médias seguidas de letras maiúsculas iguais não diferem entre si pelo teste

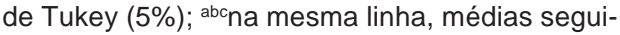
das de letras minúsculas iguais não diferem entre si pelo teste de Tukey (5\%).

qualidade dos ovos frescos notou-se que ainda com 28 dias de armazenamento os valores obtidos para Aw dos ovos deste estudo encontraram-se dentro do citado pela literatura para ovos frescos que vai do intervalo de <0,98 a 0,93 (Leitão, 1988).

\section{CONCLUSÕES}

A qualidade interna dos ovos decresce com o tempo de estocagem em temperatura ambiente de forma mais acentuada nos ovos embalados em filme plástico, já que a embalagem de ovos em condição de vácuo preservou algumas características de qualidade dos mesmos, tais como: UH, IG, $\%$ MPO. E a higienização, em muitas características avaliadas aqui, proporcionou queda na qualidade dos ovos. Conclui-se que com a higienização, as condições de armazenamento dos ovos em filme de PVC 


\section{SCATOLINI-SILVA, BORBA, GIAMPIETRO-GANECO, SOUZA, BOIAGO, MELLOE VAZ}

devem ser melhoradas, pois a queda de qualidade interna destes foi a mais afetada.

\section{BIBLIOGRAFIA}

Alleoni, A.C.C. e Antunes, A.J. 2001. Unidade Haugh como medida da qualidade de ovos de galinha armazenados sob refrigeração. Sci Agric, 58: 681-685.

Antunes, R. 2001. Avicultura industrial. <http:// www.aviculturaindustrial.com.br> (15/12/2006).

AOAC. 1984. Official Methods of Analysis $17^{\text {th }}$ edition. Association of Official Analytical Chemists. Washington.

Bertechini, A.G. 2004. Mitos e verdades sobre o ovo e consumo. <http://www.ovoonline.com.br> (15/12/2006).

Boiago, M.M.; Souza, H.B.A.; Scatolini, A.M.; Leonel, F.R.; Paschoalin, G.C.; Souza, P.A. e Kobashikawa, S.N.O. 2006. Avaliação da utilização de filme de PVC e da linhagem da ave no armazenamento de ovos. Em: IV Congresso de Produção, Consumo e Comercialização de Ovos. Anais... Associação Paulista de Avicultura. Indaiatuba, SP. Brasil. pp. 102-103.

Brasil. 1990. Portaria $\mathrm{n}^{\circ} 01$, de 21 de fevereiro de 1990. Oficializa as normas gerais de inspeção de ovos e derivados. Diário Oficial, Brasília. 44. pp. 4321 (Seção1, de 06/03/1990).

Card, L.E. y Nesheim, M.C. 1978. Produción avícola. Editoral Acribia. Zaragoza. España. 392 pp.

Englert, S. 1998. Avicultura: tudo sobre raça, manejo e alimentação. Agropecuária. Guaibá. Brasil. 238 pp.

Haugh, R.R. 1937. The Haugh unit for measuring egg quality. US Egg Poultry Mag, 43: 552-555.

Leitão, M.F.F. 1988. Microbiologia aplicada à esterilização dos alimentos. Em: Roitman, I.; Travassos, L.R. e Azevedo, J.L. Tratado de microbiologia. Manole. São Paulo.

Leonel, F.R.; Boiago, M.M.; Scatolini, A.M.;Bordon, V.F. e Souza, H.B.A. 2007. Efeito da aplicação do vácuo na manutenção da qualidade interna de ovos comerciais sob armazenamento. Em: V Congresso de Produção, Consumo e Comer-

\author{
AGRADECIMENTOS \\ À FAPESP pelo financiamento.
}

cialização de Ovos. Anais... Associação Paulista de Avicultura. Indaiatuba, SP. Brasil. pp. 17-18.

Moreng, R.E. e Avens, J.S. 1990. Ciência e produção de aves. Roca. São Paulo. pp. 227-249.

Pombo, C.R. 2003. Efeito do tratamento térmico de ovos inteiros na perda de peso e características de qualidade interna. Dissertação (Mestrado em Medicina Veterinária). Niterói, RJ. 74 pp.

SAS Institute. 1999. SAS user's guide: statistics. Release 8.02. SAS Institute. Cary. USA.

Scatolini-Silva, A.M.; Borba, H.; Giampietro, A.; Boiago, M.M.; Souza, T.A. e Souza, P.A. 2010. Embalagem à vácuo como alternativa para manutenção da qualidade de ovos armazenados em condições de ambiente. VIII Congresso de Produção e Comercialização de Ovos. Anais... Associação Paulista de Avicultura. São Pedro, SP. pp. 273-275.

Silversides, F.G. and Budgell, K. 2004. The relationships among measures of egg albumen height, $\mathrm{pH}$, and hipping volume. Poultry Sci, 83: 1619-1623.

Solomon, S.E. 1991. Egg and eggshell quality. Wolfe Publishing. London. $149 \mathrm{pp}$.

Souza, H.B.A. 1997. Influência de níveis suplementares de ácido ascórbico, de filmes plásticos protetores e óleo mineral sobre a qualidade dos ovos. 1997. Tese (Doutorado em Tecnologia de Alimentos). Universidade Estadual de Campinas. Campinas, SP. 107 pp.

Stadelman, W.J. and Cotterill, O.J. 1977. Egg science and technology. $2^{\text {a }}$ ed. New York. pp. 39-63.

Stringhini, M.L.F.; Andrade, M.A.; Mesquita, A.J.; Rocha, T.M.; Rezende, P.M. e Leandro, S.M. 2009. Características bacteriológicas de ovos lavados e não lavados de granjas de produção comercial. Ciênc Anim Bras, 10: 1317-1327.

USDA. 2000. Egg-Grading Manual. Departament of Agriculture. Washington. 56 pp. 